\title{
SITC.N
}

\section{DIGITALIZACIJA PROMOCIJE BANJA SRBIJE - NA RIMERIMA VRNJAČKE BANJE I SOKOBANJE}

\author{
Verka Jovanović*, Melita Jovanović Tončev \\ Univerzitet Singidunum, Danijelova 32, Beograd, Srbija
}

\begin{abstract}
Apstrakt:
Primena savremene tehnologije u promociji banjskih turističkih destinacija uslovila je promene kako na strani ponude, tako i na strani tražnje. Kreatorima marketing aktivnosti određene destinacije pružila je niz mogućnosti za uspostavljanje brzog, ekonomski isplativog, informativnijeg, geografski pokrivenijeg kontakta sa potencijalnim posetiocima. Sa druge strane, savremenim turistima koji imaju sofisticiranije želje i preferencije omogućila je detaljnu vizuelizaciju i upoznavanje sa destinacijom i pre odlaska u istu, kao i postavljanje fotografija, video zapisa i komentara o posećenoj banji. Ovaj rad izučava veb sajtove i društvene medije koje destinacijski menadžment može iskoristiti za potrebe promocije i postizanje vidljivosti ne samo na domaćem, već i na međunarodnom tržištu. Cilj rada je da se putem analize strukture veb sajtova, foruma, blogova, vlogova, Facebook-a , Pinteresta, Instagrama, Twitter-a Vrnjačke i Sokobanje, kao dve najposećenije banjske destinacije Srbije, ustanovi stepen digitalizacije promocije i predlože smernice za dalju upotrebu online promotivnih tehnika u Vrnjačkoj Banji i Sokobanji.
\end{abstract}

\section{Ključne reči:}

digitalizacija promocije,

društvene mreže,

banje Srbije,

Vrnjačka Banja,

Sokobanja.

\section{UVOD}

Tradicionalne marketinške komunikacije koje uspostavljaju jednostranu, veoma često neefikasnu komunikaciju sa turistima, poslednjih godina 20 . veka i početkom 21. veka bivaju obogaćene digitalnim komunikacijama čija je osnovna karakteristika brza, efikasna, dvosmerna, interaktivna komunikacija. Putnici sve češće svoje putovanje počinju pretraživanjem veb stranica određene destinacije na Internetu. Postavljanjem fotografija, deljenjem sadržaja, statusa, lokacija, informacija, turisti i sami postaju kreatori stranica društvenih mreža. Sa druge strane, učesnici na strani ponude moraju biti svesni da je pojavljivanje na društvenim mrežama proces koji kontinuirano traje i zahteva svakodnevni angažman i ažuriranje podataka. Pravilnom upotrebom društvenih mreža, kreatori marketinških aktivnosti mogu postići prepoznatljivost, atraktivnost, ojačati brend, povećati broj turista, a samim tim i prihod turističkog mesta.

Rasprostranjeno je mišljenje da su korisnici društvenih mreža uglavnom tinejdžeri i studenti i da oni nisu ekonomski nezavisni te ne mogu postati značajniji korisnici turističkih usluga. "Međutim, podaci o starosti korisnika Facebo$o k$-a pokazuju drugačiji trend. Možda je tako bilo u prvim godinama nakon uvođenja Interneta, ali studenti koji su pre pet godina koristili Facebook više nisu studenti. Većina njih je ekonomski nezavisna. Uskoro će doći do izjednačavanja u statistici između tinejdžera i ljudi od 28-45 godina. U ne tako dalekoj budućnosti imaćemo približno isti broj penzionera na društvenim mrežama."(Stojanović, 2013)

\section{FUNKCIJE DRUŠTVENIH MREŽA I NJIHOVO KORIŠĆENJE U TURIZMU}

Društvene mreže koje imaju najveći broj korisnika su $F a$ cebook, YouTube, Twitter, Google+, Pinterest, Yahoo Answers, Linkedin, Instagram, Turnbir i Tagged (Boone et al., 2015). Njihovim korišćenjem DMO može postići bolju vidljivost destinacije i približavanje korisnicima koji su sve više online.

Facebook je društvena mreža koja ima najveći broj korisnika. Najpre je bio dostupan isključivo studentima Harvarda, da bi u septembru 2006. godine bilo koji korisnik koji je imao email adresu i bio stariji od 13 godina mogao postati učesnik na Facebook-u. Osnovni elementi Facebooka su profil, status, fotografija i deljenje (Stankov et al., 2014).

Neophodno je naglasiti da otvaranje profila koji predstavljaju određeni turistički objekat prema pravilima Facebook-a nije dozvoljeno. Otvaranjem profesionalnog profila krše se pravila Facebook-a i obmanjuju poslovni saradnici i potencijalni turisti. Ograničeni broj prijatelja od 5000 ( iako je ovo delimično rešeno opcijom Subscribe-Follow), takođe limitira mogućnosti promocije putem Facebook-a. Grupa na Facebook-u (organizovanje ljudi koji imaju zajednička interesovanja) takođe ne predstavlja mesto na kome bi trebalo promovisati destinaciju.

Najadekvatnije je kreirati Facebook stranu (Facebook Page) kod koje ne postoji ograničenje u broju fanova. Oni su pozvani da lajkuju stranice, da komentarišu ili da se taguju na fotografijama. Prednosti Facebook stranice u odnosu na 
profil je što poznati pretraživači kao što je Google, indeksiraju strane, a ne i profil. Na taj način, korišćenjem pretraživača Google, Facebook strana može se naći na boljoj poziciji nego veb-sajt destinacije.

Osnovni cilj Facebook-a je prikupiti što više lajkova. Međutim, destinacijskom menadžmentu nije važan broj lajkova, već broj turista koji će posetiti destinaciju, pročitati svaki status, lajkovati, deliti (šerovati), proslediti i preporučiti prijateljima i na taj način dovesti nove turiste.

Twitter je društvena mreža koja beleži sve veći broj korisnika i koji ima svoju primenu i u turizmu. Početak korišćenja Twittera predstavlja otvaranje profila i postavljanje naslovne i profilne slike. Dok je na Facebooku sadržaj u vidu fotografije, video klipova i slično na Twitter-u je prioritet na informacijama. Status (tvit) na Twitter- $u$ je ograničen ograničen na 140 karaktera uključujući i linkove koji se postavljaju (Stojanović, 2013). Praćenjem (followunfollow) moguće je saznati šta neko piše. Korišćenjem haštaga \# ispred nekog pojma klasifikuju se tvitovi na osnovu različitih kriterijuma (\#Sajam Turizma). Klikom na taj link moguće je pročitati šta su ostali korisnici tvitovali pod tim haštagom.

$\mathrm{Na}$ Twitter-u se otvaraju profili, a ne strane kao na Facebook-u. Komunikacija je ležernija, ali jasna i precizna. Kako bi korišćenje Twittera u promociji destinacije bilo efikasno, neophodno je tvitovati o "turističkoj ponudi, informacijama o turizmu, pratiti osobe i organizacije koje se bave turizmom, kao i konkurenciju" (Stojanović, 2013).

Instagram je društvena mreža za deljenje fotografija i može se reći da je jednim delom Flickr, a drugim Twitter. Kako bi se napravila dobra strategija sadržaja na Instagramu, potrebno je identifikovati potencijalne pratioce na osnovu afiniteta pratilaca konkurenata. Postavljanjem fotografija koje njih interesuju, moguće ih je navesti da postanu pratioci destinacije koja se promoviše. Veoma je važno da se objavljuju fotografije odmah nakon fotografisanja, jer tada pratioci stiču utisak da im se prezentuje aktuelna situacija. Na Instagramu je moguće postaviti kratke video klipove koji predstavljaju sadržaj koji je do sada nedostajao na Instagramu. Korišćenjem dve vrste haštagova (haštag koji nosi ime Brenda i uopštenih haštagova koji su relevantni za ponudu), postiže se veoma laka dostupnost fotografija potencijalnim korisnicima turističkih usluga.

Pinterest je društvena mreža koja je osnovana 2010. godine. To je mreža oglasnih tabli (boards) koja služi korisnicima da prikupljaju ideje, zanimljivosti i informacije u vidu fotografija o odeđenoj turističkoj lokaciji. Table kreiraju sami korisnici prema sopstvenim interesovanjima. Fizička lica na Pinterestu postavljaju nalog i kreiraju privatni profil, dok je za poslovne svrhe najbolje napraviti poslovnu stranu (Business Page). Postavljanje fotografija na Pinterestu naziva se pinovanjem, a same fotografije pinovi. Oni se razvrstavaju po albumima (tablama). "U praksi, kada korisnik pronađe nešto interesantno on može da pinuje svoje interesovanje u svoju tablu. Od kombinacije reči pin i interest nastao je i naziv ove društvene mreže." (Minazzi, 2015). Deljenje fotografija (šerovanje na Facebook-u i retvitovanje na Twitter-u) se postiže putem repinovanja.

Za korisnike koji žele da svoju promociju obavljaju i putem Pinteresta veoma je važno da:

- integrišu Pinterest sa sajtom i ostalim društvenim mrežama,
- pinuju samo kvalitetne fotografije,

- uvek imaju na umu da je Pinterest društvena mreža,

- prate, mere i ocenjuju svoje aktivnosti,

- postavljaju relevantan sadržaj,

- prave odgovarajuće albume (table),

- budu konstantni (Stojanović, 2013).

Foursquare je geolokacijska društvena mreža, koja u osnovi ima deljenje trenutnih lokacija sa prijateljima uz pomoć GPS-a sa mobilnog telefona(Stojanović, 2013). Osnovna aktivnost na Foursquare je check-in. Ukoliko turista boravi na nekoj novoj lokaciji, on se čekira. Na ovoj mreži se može pratiti i kretanje prijatelja. Ostali korisnici mogu lajkovati (klikom na znak srce).

Za turiste je veoma bitna ova društvena mreža, jer na njoj mogu pročitati komentare ostalih korisnika o određenoj destinaciji i njihovoj turističkoj infrastrukturi. Čekiranjem na deset različitih lokacija, turista postaje vlasnik Adventure bedža, dok će postati Explorer ukoliko se čekira na 25 različitih lokacija. Čekiranjem u 20 različitih picerija može postati vlasnik tematskog bedža. Putnik koji se čekira više puta u jednom istom objektu u poslednjih 60 dana postaje vlasnik titule Mejdžora za neki objekat. Na taj način se turisti motivišu da se čekiraju i ostavljaju komentare o određenim lokacijama. Svoja iskustva mogu podeliti sa ostalim korisnicima ove mreže klikom na opciju Leave a tip.

Google+ je društvena mreža jedne od najvećih informacionih kompanija u svetu - Google. Broj njenih korisnika je sve veći (343 miliona). Postati korisnik navedene mreže je veoma bitno, jer će prilikom pretraživanja na osnovu određene ključne reči biti favorizovana strana ove društvene mreže, a ne neke druge. Zatim, sve je više korisnika Google Translate, Google Maps, Google Docs. Google pomenute servise sve više vezuje za svoju društvenu mrežu čime privlači ljude da se registruju i koriste ovu društvenu mrežu (Stojanović, 2013).

$\mathrm{Na}$ Google+ je takođe važno za privredne subjekte da kreiraju Google+ stranu, a ne profil. Ova mreža funkcioniše po principu krugova. Prilikom predstavljanja određene turističke destinacije važno je napraviti krugove putem kojih je moguće pratiti "sve relevantne subjekte unutar destinacije (smeštajno-ugostiteljske objekte, saobraćajna preduzeća, organizacije, ustanove, institucije), ali i druge destinacije u okolini” (Stojanović, 2013).

\section{ISTRAŽIVANJE O UPOTREBI VEB-SAJTOVA I DRUŠTVENIH MREŽA U PROMOCIJI VRNJAČKE BANJE I SOKOBANJE}

Implementacija informacione tehnologije u turističku privredu Srbije počevši od 1996. godine (kada je Internet prvi put uvede u Srbiji), za rezultat je imala promene u rezervacionim, distributivnim sistemima, kao i u promociji ponude i načinu kupovine turističkih usluga. Želeći da zadovolji težnju turista za detaljnim i aktuelnim informacijama, turistička organizacija Srbije (TOS) je doprinela kreiranjem veb portala koji će se "koristiti za prezentaciju turističkog potencijala Srbije, privlačenje domaćih i inostranih gostiju i za pružanje korisnih informacija. Najpoznatiji domaći veb portali su VisitSerbia.org i TouristGuide. com"(Milićević et al., 2013). 
Svako ko počinje u svojim promotivnim aktivnostima da koristi Internet, najpre postavi veb-sajt. Kako bi veb-sajt na adekvatan način vršio svoju funkciju, a to je efikasna promocija date destinacije, neophodno je da ispuni određene uslove koji se tiču kako tehničkih karakteristika, tako i sadržajnih. Ukoliko se želi efektivno organizovati promocija putem sajtova destinacijski menadžment (ili angažovani stručni saradnik) bi trebalo da optimizira online marketing strategiju, navigaciju sajta, sadržaj stranice, istovremeno je integrišući sa offline marketing strategijom, PR-om i kanalima komunikacije (Kliffton, 2014).

Želeći da ukažemo na značaj koji dobro struktuiran vebsajt može imati za promociju određene turističke destinacije, analizirali smo sajt Vrnjačke Banje po zadatim kriterijumima prikazanim u tabeli 1. Osnovni parametri koji su razmatrani prilikom ove analize se odnose na tehničke karakteristike, kao i na mogućnosti primene određenih instrumenata promocije. Tehničke karakteristike sajta su analizirane posmatranjem samog obeležavanja, zatim strukture sajta, kao i vidljivosti na primarnim i nacionalnim pretraživačima, dok su mogućnosti primene instrumenta promocije analizirane putem tehnika internet oglašavanja. Posebno su analizirane pogodnosti i promene koje sajt nudi u domenu distribucije (mogućnosti online rezervacija, pretraživanja ponude i sl.).

Analizom veb prezentacije Vrnjačke banje došli smo do zaključka da je domen adekvatan. Struktura veb-sajta je dobro organizovana, jer postoji glavni meni koji vodi turistu u odeljke koje on klikom bira. Sajt je dinamičan, dolazi do smene različitog sadržaja. Ponuda je veoma detaljno opisana, kao i svi proizvodi koje nudi banja kao destinacija. Sajt Vrnjačke Banje omogućava turistima upoznanje sa destinacijom i pre posete putem virtuelnih tura. Opcije online rezervacije takođe postoje. Boje upotrebljene na sajtu omogućavaju jasno čitanje sadržaja sajta. Postoji previše banera koji oglašavaju smeštajnu ponudu banje. Njihov broj bi trebalo prilagoditi koncepciji sajta. Sajt Vrnjačke Banje je 2012. godine dobio nagradu „Najbolje na domaćem vebu“.

Posmatranjem i analizom elemenata internet prezentacije Sokobanje došli smo do zaključka da je tehnički dobro struktuiran sa adekvatnim sadržajem prema tipu sajta. Takođe je i zadovoljavajući kvalitet prezentacije sadržaja, jer postoji glavni meni na svim stranicama, kao i opcija brze pretrage. Mogućnosti promocije putem ovog sajta su prikazane u tabeli broj 2.

Domen sajta Sokobanje je adekvatan bez ekstenzije nacionalnog karaktera. Sajt nudi opciju brze pretrage. Vidljivost sajta je veoma dobra. Broj banera je veliki. Najveći nedostatak ove prezentacije je nepostojanje mogućnosti pristupa sadržaju na nekom od stranih jezika.

Upotreba društvenih mreža u svrhu promocije banjskih destinacija analizirana je takođe na primeru Vrnjačke Banje i Sokobanje, kao destinacije sa najvećim brojem turista i broja noćenja (prema podacima Republičkog zavoda za statistiku). Analizirano je korišćenje Facebook--a, Twitter-a, Instagrama, Pinteresta, Foursquare, postojanje blogova i vlogova u vezi promocije pomenutih destinacija.

Tabela 1. Analiza strukture veb-sajta Vrnjačke Banje

\begin{tabular}{|c|c|c|}
\hline Kategorija & Elementi posmatranja & Predvidena situacija \\
\hline 1. Domen & Adekvatnost domena prema predmetu sajta & Adekvatno* - Neadekvatno \\
\hline 2. Tip veb-sajta prema funkcionisanju & & Statičan - Dinamičan* \\
\hline 3. Početna stranica (doorway) & & Postoji - Ne postoji \\
\hline 4. Adekvatnost sadržaja prema tipu sajta & & Adekvatan* - Delimično adekvatan \\
\hline \multicolumn{3}{|l|}{ 5. Kvalitet prezentacije sadržaja } \\
\hline \multicolumn{3}{|c|}{ a) Navigacija } \\
\hline & Glavni meni na svim stranicama & Postoji ${ }^{*}$ Ne postoji \\
\hline & Funkcionalnost & Postoji ${ }^{\star}$ Ne postoji \\
\hline & Opcija brze pretrage & Postoji - Ne postoji \\
\hline & Mapa veb-sajta & Postoji ${ }^{\star}$ Ne postoji \\
\hline & b) Dostupnost sadržaja na stranim jezicima & $\begin{array}{l}\text { Potpuna - Delimična } \\
\text { Engleski - under construction }\end{array}$ \\
\hline & c) Osnovne boje sajta & Bela i tamne boje \\
\hline & d) Kontrast boja & Dobar* - Loš \\
\hline \multicolumn{3}{|c|}{ 6. Vidljivost na primarnim i nacionalnim pretraživačima } \\
\hline & Google & Postoji - Ne postoji \\
\hline & Yahoo & Postoji - Ne postoji \\
\hline & Metasearch.rs & Postoji ${ }^{\star}$ Ne postoji \\
\hline & Krstarica & Postoji - Ne postoji \\
\hline \multicolumn{3}{|l|}{ 7. Tehnike Internet oglašavanja } \\
\hline & Linkovi drugih sajtova & Postoji ${ }^{*}$ - Ne postoji \\
\hline & Postojanje banera & Postoji ${ }^{\star}$ Ne postoji \\
\hline & Broj banera & Broj banera: 14 \\
\hline & Tip banera & Statični - Dinamični* \\
\hline \multicolumn{3}{|l|}{ 8. Tehnika odnosa sa javnošću } \\
\hline & Sekcija za vesti & Postoji - Ne postoji \\
\hline & Chat & Postoji ${ }^{*}$ Ne postoji \\
\hline & Forumi & Postoji - Ne postoji \\
\hline & Anketa & Postoji ${ }^{*}$ Ne postoji \\
\hline 9. Distributivni elementi veb-sajta & Online rezervacija & Postoji ${ }^{*}$ Ne postoji \\
\hline
\end{tabular}

${ }^{*}$ označene karakteristike koje analizirani veb-sajt poseduje.

Izvor: Sopstvena analiza na osnovu: Stankov (2008, str. 8) 
Tabela 2 Veb-sajt Sokobanje

\begin{tabular}{|c|c|c|}
\hline Kategorija & Elementi posmatranja & Predvidena situacija \\
\hline 1. Domen & Adekvatnost domena prema predmetu sajta & Adekvatno* - Neadekvatno \\
\hline 2. Tip veb-sajta prema funkcionisanju & & Statičan - Dinamičan ${ }^{*}$ \\
\hline 3. Početna stranica (doorway) & & Postoji $^{*}$ - Ne postoji \\
\hline 4. Adekvatnost sadržaja prema tipu sajta & & Adekvatan* - Delimično adekvatan \\
\hline \multicolumn{3}{|l|}{ 5. Kvalitet prezentacije sadržaja } \\
\hline \multicolumn{3}{|c|}{ a) Navigacija } \\
\hline & Glavni meni na svim stranicama & Postoji $^{*}$ - Ne postoji \\
\hline & Funkcionalnost & Postoji $^{*}$ - Ne postoji \\
\hline & Opcija brze pretrage & Postoji $^{*}$ - Ne postoji \\
\hline & Mapa veb-sajta & Postoji $^{\star}$ - Ne postoji \\
\hline & b) Dostupnost sadržaja na stranim jezicima & Potpuna - Delimična \\
\hline & c) Osnovne boje sajta & $\begin{array}{l}\text { Ne postojl sajt na stranom jeziku } \\
\text { Bela i plava }\end{array}$ \\
\hline & d) Kontrast boja & Dobar $^{\star}$ - Loš \\
\hline \multicolumn{3}{|c|}{ 9. Vidljivost na primarnim i nacionalnim pretraživačima } \\
\hline & Google & Postoji $^{*}$ - Ne postoji \\
\hline & Yahoo & Postoji $^{*}$ - Ne postoji \\
\hline & Metasearch.rs & Postoji $^{*}$ - Ne postoji \\
\hline & Krstarica & Postoji $^{*}$ - Ne postoji \\
\hline \multicolumn{3}{|l|}{ 10. Tehnike Internet oglašavanja } \\
\hline & Linkovi drugih sajtova & Postoji - Ne postoji ${ }^{*}$ \\
\hline & Postojanje banera & Postoji $^{*}$ - Ne postoji \\
\hline & Broj banera & Broj banera: 12 \\
\hline & Tip banera & Statični* - Dinamični \\
\hline \multicolumn{3}{|l|}{ 11. Tehnika odnosa sa javnošću } \\
\hline & Sekcija za vesti & Postoji $^{\star}$ - Ne postoji \\
\hline & Chat & Postoji $^{\star}$ - Ne postoji \\
\hline & Forumi & Postoji $^{*}$ - Ne postoji \\
\hline & Anketa & Postoji $^{\star}$ - Ne postoji \\
\hline & Mogućnost učlanjenja & Postoji $^{*}$ - Ne postoji \\
\hline 12. Distributivni elementi veb-sajta & Online rezervacija & Postoji $^{*}$ - Ne postoji \\
\hline
\end{tabular}

* označene karakteristike koje analizirani veb-sajt poseduje.

Izvor: Sopstvena analiza na osnovu: Stankov (2008, str. 8)

Facebook stranica Vrnjačke Banje je analizirana i primarno istraživanje koje je sprovedeno 01.07.2015. godine ukazuje da je tog dana imala 6699 lajkova. Poslednja objava je bila 27.06.2015. što ukazuje da se pomenuta strana redovno ažurira. Na Facebook strani postoji link ka veb strani www.vrnjackabanjainfo.com, čime se posetioci Facebook-a usmeravaju na informacije prezentovane i na veb strani. Takođe postoji i opcija poziv prijateljima da označe ovu stranicu što je veoma važno prilikom deljenja sadržaja. Osim linka ka veb-sajtu, postoji i link ka \#vrnjackabanja\#spa\#srbija\#leto čime se posetilac upućuje sve informacije koje su objavljene pod ovim haštagovima.

Na Facebook stranici Vrnjačke banje je ispoštovano preporučeno pravilo da fotografije čine $90 \%$ sadržaja, a promocija, odnosno tekst samo $10 \%$. Objave su vezane za manifestacije koje će se organizovati (Karneval od 12-19. jula 2015.), kao i za religijske svetinje koje se nalaze u blizini Vrnjačke Banje. Twitter Vrnjačke Banje koji nosi oznaku @vrnjacka_banja ima 1425 tvitova, 22 onih koje prate i 391 pratilaca. Na ovom profilu postoji i link koji vodi ka sajtu www.vrnjacka-banja.co.rs. Poslednji tvit na ovom profilu je bio 14.06.2015. godine, što ukazuje da se na ovoj društvenoj mreži s vremena na vreme tvituje.
Tabela 3. Upotreba društvenih mreža u promociji Vrnjačke Banje i Sokobanje

\begin{tabular}{lll}
\hline & VRNJAČKA BANJA & SOKOBANJA \\
\hline Facebook & $\begin{array}{l}\text { 6,7 K, } \\
\text { otvorena 2012. }\end{array}$ & $\begin{array}{l}\text { 4,4 K, } \\
\text { otvorena stranica 2009. }\end{array}$ \\
\hline Twitter & $\begin{array}{l}\text { @vrnjacka_banja, 1425 } \\
\text { tvitova, 22 onih koje } \\
\text { prate i 391 pratilaca. }\end{array}$ & Ne koriste \\
\hline Instagram & $\begin{array}{l}\text { 290 pratilaca, 25 } \\
\text { postova, link ka sajtu, } \\
\text { ne koriste \# }\end{array}$ & $\begin{array}{l}\text { 24 pratilaca, link ka } \\
\text { sajtu, ne koriste \# }\end{array}$ \\
\hline Pinterest & Ne koriste & Ne koriste \\
\hline Google+ & Ne koriste & $\begin{array}{l}1 \text { krug-smeštajni } \\
\text { kapaciteti, 128 ljudi }\end{array}$ \\
\hline Foursquare & Ne koriste & Ne koriste \\
\hline Blog & Ne koriste & Ne koriste \\
\hline Vlog & Ne koriste & Ne koriste \\
\hline Forum & $\begin{array}{l}\text { Forum Krstarice, tema } \\
\text { Vrnjačka Banja }\end{array}$ & $\begin{array}{l}\text { 17911 poruka, 2394 } \\
\text { tema, 2229 članova, } \\
\text { poruka }\end{array}$ \\
\hline
\end{tabular}

Izvor: Sopstvena analiza na osnovu: Facebook (2015a); Facebook (2015b); Twiter (2015); Sokobanja (2015) 
Analizom Facebook stranice Sokobanje je utvrđeno da je ona otvorena 2009. godine, kao i da ima 4400 pratilaca. Na ovoj stranici se najčešće najavljuje održavanje određenih manifestacija i promoviše Akva park kojim se želi privući mlađa populacija turista u ovu banjsku destinaciju. Za razliku od Vrnjačke banje, Sokobanja ne koristi Twitter, ali je kreiran profil na Google+. Na forumu Sokobanje je obrađeno 2349 tema i zabeleženo 17911 poruka.

\section{SMERNICE ZA KORIŠĆENJE DRUŠTVENIH MREŽA U PROMOCIJI BANJA SRBIJE}

Uzrok ne postizanja ciljeva određenih veb prezentacija ne nalazi se u odsustvu kreativnosti ljudi koji su osmislili i postavili veb prezentaciju, već u nedostatku strukturisanog razmišljanja o tome šta su istinski ciljevi koji se žele postići veb kampanjom, kao i nedostatak merenja performansi veb-sajta koje bi identifikovalo uzroke neuspeha (Kaushik, 2015). Zbog toga je veoma važno stalno biti u kontaktu sa korisnicima, osluškivati njihove želje i preferencije, poboljšavati performanse sajta kako bi se zadovoljile želje i preferencije posetilaca i bila im pružena tražena informacija.

Ukoliko se Facebook-om žele postići četiri osnovne funkcije društvenih mreža, a to su: evaluacija, odgovor, širenje i vođenje potrošačevog ponašanja (Dival et al., 2012), neophodno je promociju putem ove društvene mreže organizovati u svrhu pružanja značajnih i korisnih informacija koje potencijalnim turistima mogu biti od pomoći. Potrebno je slediti pravilo 80:20 odnosno stranicu organizovati da prikazuje $80 \%$ tekstualnog sadržaja u vidu korisnih informacija i $20 \%$ promocije turističkog banjskog proizvoda. Veoma je važno „slušati“ svoje fanove, redovno odgovarati, biti zanimljiv i duhovit. Takođe je značajno organizovati stranicu da bude bogatija fotografijama i video klipovima. Prema nedavnoj studiji Hub Spot-a, postovi sa slikama imaju 53\% više lajkova i 104\% više komentara od tekstualnih (Stojanović, 2013).

Korišćenje anketa kako bi se prikupilo mišljenje fanova, praćenje komentara koje posetioci banjskih destinacija postavljaju na odgovarajućim servisima, predstavlja povratnu informaciju koja će pomoći da se razume stav turista prema destinaciji, kao i iskustvo koje su oni doživeli posetom. Povezanost veb sajta sa Facebook stranom (i ostalim društvenim mrežama) je veoma bitno za postizanje vidljivosti na evropskoj turističkoj mapi. Moguće je ponuditi i popust turistima koji se čekiraju u destinaciji i to podeliti na Facebooku, Twitteru, Foursqueru. Postavljanje reklame sa desne strane (Facebook ads), takođe može doprineti efikasnosti promocije. Facebook ad je veoma sličan banerima koji se postavljaju na sajtovima, ali je bolji način prikupljanja pravih fanova strane. Dodatna promocija svakog pojedinačnog statusa može se postići opcijom boost post (Stojanović, 2013), koja se koristi kada se želi obavestiti veći broj fanova o promociji, popustima, specijalnim ponudama.

Veoma je važno imati na umu da je korišćenje društvenih mreža stalni proces i da se mora neprekidno tvitovati. Google indeksira tvitove i stoga je neophodno koristiti ključne reči prilikom tvitovanja. “Zbog veoma kratke dužine poruke od 140 karaktera, mikro-blogeri kako se još i nazivaju korisnici Twitter-a, veoma često postavljaju link ka sajtu ili ka tradicionalnim blogovima kako bi se omogućila potpuna informacija o određenim temama" (Minazzi, 2015, str. 10). Ukoliko ciljnu grupu turista čine stranci, potrebno je tvitovati i na engleskom, francuskom, italijanskom. Osim toga, ukoliko da putem Twitter-a postignemo efikasniju promociju sopstvene destinacije, neophodno je da pratiti praznike i slobodne dane u tim zemljama i na osnovu toga pripremiti odgovarajuću turističku banjsku ponudu. „Jedna od najčešćih tema na Twitter-u je uticaj koji pojedini korisnici ove društvene mreže imaju u poređenju sa ostalim korisnicima. Uticaj podrazumeva da te osobe mogu svojim tvitovima, sugestivno privoleti korisnike na neku akciju, promenu mišljenja, kupovinu proizvoda" (Stojanović, 2013).

"Na Instagramu je moguće čekirati opciju Add to your photo Map čime se postiže označavanje lokacije na fotografijama i potpuno novi nivo interaktivnosti sa pratiocima" (Stojanović, 2013). Takođe je moguće osmisliti i nagradnu igru što bi podstaklo pratioce da postavljaju fotografije koje odgovaraju određenoj tematici.

Postavljanje fotografija na Pinterestu i njihovo organizovanje u albume će privući veću pažnju potencijalnih turista i povećaće interakciju sa njima. To će podstaći korisnike da lajkuju, šeruju i komentarišu. Svaka promotivna aktivnost podržana setom fotografija biće efikasnija i doprineće prepoznatljivosti destinacije. Veoma bitna osobina Pinteresta je što "svaki pin u sebi sadrži adresu sajta sa kojeg je pinovan, tako da korisnici Pinteresta jednim klikom bivaju preusmereni na određeni sajt" (Stojanović, 2013). Ova mreža omogućava subjektima na strani ponude da saznaju kada je potencijalni turista zainteresovan za posetu određenoj destinaciji. Ukoliko je dodao pinovanjem u listu destinacija koje planira da poseti to se može videti u tablama koje se nazivaju "Mesta za letovanje", "Mesta koja moram posetiti". Na kreatorima destinacijske ponude je da težnja turista da posete određenu destinaciju bude i realizovana na osnovu njihove odgovarajuće ponude.

Destinacija koja za svoju promociju koristi Foursquare društvenu mrežu bi trebalo da beleži čekinove (prijave), lajkove, komentare kako bi bila svrstana u liste koje kreiraju korisnici. „Što se više interakcije beleži, bolje će biti pozicionirana na rezultatima pretrage na ovoj društvenoj mreži” (Stojanović, 2013).

Postavljanjem fotografija, video zapisa ili nešto dužih tekstualnih opisa na Google +, moguće je turistima pružiti detaljnije i potpunije informacije o destinaciji. Promociju različitih manifestacija je moguće prikazati putem opcije Kreiranje događaja (Event). Kao i kod ostalih društvenih mreža veoma je važno povezati Google+ vidžet+1 sa vebsajtom. Na taj način je posetiocima sajta pružena informacija o aktivnostima na ovoj društvenoj mreži.

Međutim, kako se broj društvenih mreža iz dana u dan povećava, tako se od DMO-a zahteva i veća radna i vremenska angažovanost na upravljanju marketingom putem ovih medija. Prema McCabeu, "menadžment socijalnih medija može pomoći upravljanje ulaznim i izlaznim online interakcijama zajedno sa ostalim marketinškim aktivnostima na veoma efikasan način" (McCabe, 2010). Dakle, promocija putem veb prezentacija i društvenih mreža nije jednokratan čin koji se završava postavljanjem veb prezentacije ili otvaranjem stranica na socijalnim medijima, već zahteva analitički pristup, redovnu angažovanost i integrisanost sa ostalim kanalima promocije. 


\section{ZAKLJUČAK}

Vrnjačka Banja i Sokobanja, kao destinacije sa najvećim brojem posetilaca u Srbiji, promociju svoje turističke ponude ostvaruju i putem kreiranja veb prezentacija, kao i korišćenjem mogućnosti društvenih mreža. Analizom određenih karakteristika veb prezentacija utvrđeno je da su sajtovi pomenutih banja adekvatno struktuirani, kao i da veoma precizno prikazuju banjsku turističku ponudu. Reč je o dinamičnim tipovima sajtova, veoma dobro dizajniranim, koji omogućavaju posetiocima potpune informacije kako o sadržaju banjskog proizvoda, tako i o njegovoj distribuciji, odnosno mogućnostima rezervacije i online kupovine. Dakle, kreativnost i informatička pismenost kadrova koji su učestvovali u kreiranju pomenutih veb prezentacija je veoma dobra i ne može biti okarakterisana kao nedostatak. Međutim, u cilju poboljšanja komunikacije sa potencijalnim posetiocima trebalo bi uvesti interaktivniji pristup. Na taj način bi korisnici banjskih usluga komentarisali svoja iskustva u vezi turističke ponude i boravka u destinaciji. Jedno od mogućih rešenja je redovno anketiranje ili postavljanje linka ka forumima na kojima se komentariše banjska turistička ponuda.

Osim interaktivnosti, sledeća osobina koju bi trebalo da poseduje dobro strukturirana veb prezentacija je kontinuiranost. Online oglašavanje je proces i neophodno je da destinacijski menadžment bude fokusiran ka dnevnom ažuriranju internet prezentacije. To bi omogućilo potencijalnim korisnicima informacije u realnom vremenu o zbivanjima $\mathrm{u}$ analiziranim destinacijama.

Onlajn promocija putem društvenih mreža je još uvek u začetku. Kao što se može i zaključiti iz prikazanih podataka Facebook je mreža koja se uglavnom koristi. Twitter u promociji koristi Vrnjačka Banja, dok je Sokobanja počela upotrebu Google+, što je veoma značajno prilikom pretraživanja Googla od strane potencijalnih turista. Upotreba Instagrama nije toliko značajna, dok se ne koriste mogućnosti Pinteresta. Analiza upotrebe društvenih mreža je i pokazala osnovne nedostatke u korišćenju društvenih mreža u promociji banjskih destinacija. Uglavnom je reč o ad hoc nestrukturiranoj i neadekvatno vođenoj promociji. Umesto takvog pristupa, neophodno je ustanoviti integrisanu komunikaciju sa korisnicima putem društvenih mreža koja će sve marketinške napore na Facebook-u, Twitter-u, Pinterestu, Google+, povezati u smislenu celinu i društvene mreže koristiti kao medije. Osim pisanja blogova i postavljanja video sadržaja na vlogovima, potrebno je aktivirati korisnike da sami putem društvenih mreža postanu zagovornici posete destinaciji. Osim toga neophodno je i ulagati određena novčana sredstva i u plaćene oglase na pretraživaču Google, Facebook-u i ostalim društvenim mrežama.
Dakle, ukoliko žele da postanu destinacije banjskog turizma prepoznatljive i na svetskom turističkom tržištu, Vrnjačka Banja i Sokobanja bi trebalo da svoju promotivnu aktivnost putem društvenih mreža strategijski isplaniraju, ali i mere, kontrolišu i koriguju. Neophodno je upravljanje marketingom onlajn aktivnosti, kao i integrisanje sa oflajn promotivnim aktivnostima.

\section{LITERATURA}

Boone, L., \& Kurtz, D. (2015). Contemporary Marketing. Boston, MA: Cengage Learning.

Clifton, B. (2014). Advanced web Metrics with Google Analytics. Indianapolis: Wiley.

Dival, R., Edelman, D., \& Sarazzin, H. (2012). Demystifying social media. Preuzeto 16. juna 2015. sa www.mckinsey. com

Facebook. (2015a). Vrnjačka Banja. Preuzeto 23. juna 2015. sa https://www. facebook.com/vrnjackabanjaonline

Facebook. (2015b). Sokobanja. Preuzeto 23. juna 2015. sa https://www.facebook.com/sokobanja.018?fref=ts

Kaushik, A. (2015). Digital Marketing and Measurement Model. Preuzeto 16. juna 2015. sa www.kaushik.net/ avinash/digital-marketing-and-measurement-model

McCabe, L. (2010). What is Social Media Management, and Why Should you care? Preuzeto 29. Juna 2015. sa www. smallbusinesscomputing.com

Milićević, S., Podovac, M., \& Sekulić, D. (2013). Uloga i značaj informacionih tehnologija na razvoj turizma Srbije. 13th International Conference Research and Development in Mechanical Industry, RaDMI 2013, Kopaonik, Serbia.

Minazzi, R. (2015). Social Media Marketing in Tourism and Hospitality. Cham: Springer.

Soko-banja. (2015). Sokobanja. Preuzeto 23. juna 2015. sa https:// soko-banja.org/index.php?option=com_smf\&Itemid=203

Stankov, U. (2008). Uloga Interneta u promociji turizma Srbije: magistarska teza. Novi Sad: Fakultet za geografiju, turizam i hotelijerstvo.

Stankov, U., Jovanović, T., \& Dragićević, V. (2014). Facebook travel related usage patterns of tourism students. Uticaj interneta na poslovanje u Srbiji i svetu: Medunarodna naučna konferencija Univerziteta Singidunum Sinteza 2014. doi: 10.15308/SINTEZA-2014-743-749.

Stojanović, M. (2013). Primena društvenih mreža u turizmu i ugostiteljstvu. Preuzeto 16. juna 2015. sa www.turizamiputovanja.com

Twitter. (2015). Vrnjačka Banja. Preuzeto 23. juna 2015. sa https://twitter.com/vrnjacka_banja,

\section{DIGITALIZATION OF PROMOTION OF SERBIAN SPAS - VRNJAČKA BANJA AND SOKOBANJA}

\begin{abstract}
:
The use of modern technology in promoting spa tourism destinations has brought about certain changes, both on the supply and demand side. It provided creators of marketing activities of specific destinations with a range of options for establishing a rapid, cost-effective, informative and geographically-covered contact with potential visitors. At the same time, modern tourists, with sophisticated needs and preferences, got the opportunity for more detailed visualization and getting to know the destination prior to visiting it, as well as for uploading photos, videos, and comments about the spa. The subject of this paper are web sites and social media, which can be used by destination management to promote and achieve greater visibility on both domestic and international markets. The aim is to analyze the structure of web sites, forums, blogs, vlogs, Facebook, Pinterest, Instagram, and Twitter profiles of Vrnjačka Banja and Sokobanja, as the two most visited Serbian spas, in order to determine the level of digitalization of promotion, and propose guidelines for further use of online promotion techniques in these two spas.
\end{abstract}

\section{Key words:}

digitalization of promotion,

social networks,

Serbian spas,

Vrnjačka Banja,

Sokobanja. 